Egyptian

Orthodontic Journal

\title{
MANDIBULAR DIMENSIONS AND FACIAL HEIGHT OF CLEFT LIP AND PALATE SUBJECTS
}

\author{
Eman A. AlKofide, BDS, MS, FCMDOP, D.Sc. *
}

ABSTRACT

The aim of this study was to measure the mandibular dimensions and the anterior facial height of cleft lip and palate patients, and to compare them with a non-Cleft control group. A total of 93 patients (57 males and 36 females) with clefts aged 11-27 years, were evaluated through cephalometric radiographs. The types of cleft included unilateral cleft lip and palate (UCLP), bilateral cleft lip and palate (BCLP), and cleft lip only (CL). A group of 28 normal subjects (18 males and 10 females) were used as a control group. All groups were matched according to gender and age. Results reveal that there were no significant differences between the cleft groups except in the mandibular plane angle (SN-SMand), where BCLP subjects displayed higher angles than $C \mathcal{L}$ only. A significantly larger mandibular plane angle was observed when comparing subjects with BCLP and VCLP and the controls $(\mathcal{P}<0.01)$. No significant difference was found between the SNNB of the cleft groups or the controls. The cleft subjects displayed smaller mandibular and ramal length (CO-GN and CO-GO), and shorter upper anterior facial height $(\mathcal{N}-\mathcal{A})$ compared with the controls. Male cleft subjects showed larger dimensions than female cleft subjects in all linear dimensions, but were still considered smaller than the control group. We can conclude that cleft subjects display certain characteristics such as high mandibular plane angles and smaller mandibular dimensions, more so than subjects without clefts.

\footnotetext{
*Associate Professor, Orthodontic Division, King Saud University, College of Dentistry, Riyadh, Saudi Arabia.
} 
Egyptian

Orthodontic Journal

\section{INTRODUCTION}

Cleft lip with or without cleft palate is the most common congenital malformation among orofacial anomalies throughout the world. It affects craniofacial growth, especially in the midface area, resulting in functional, esthetic, as well as psychosocial disturbances. ${ }^{(10,28)}$ The etiology of clefts is known to be multifactorial, involving hereditary and environmental factors. ${ }^{(18)}$ Clefting occurs in all races, both genders, and all socio-economic groups. However, the incidence follows distinct ethnic distribution patterns. Cleft lip and palate occurs at a rate of approximately 1.0 per 1,000 births in the European and North American Caucasian populations, while a lower incidence of 0.5 per 1,000 births is present in the African-American population. ${ }^{(13,14,22,27,36)}$ Information on clefts and craniofacial anomalies in Saudi Arabia was published in a recent investigation undertaken at King Faisal Specialist Hospital and Research Center during a six-year period from 1999-2005. ${ }^{(17)}$ A total of 807 cases of clefts were registered; 451 males and 356 females; with a male to female ratio of 1.3:1.

It is known that clefts, especially those involving both lip and palate, influence growth of the maxilla and the midface region. The effect of clefts on the mandible has also been documented in previous investigations. ${ }^{(5,12,19,21,29,34)}$ Filho et al (1993) reported that cleft patients, regardless of cleft type, have smaller mandibles than non-cleft subjects. ${ }^{(1)}$ Smahel and Brejcha (1983) concluded that subjects with complete UCLP displayed certain mandibular morphological characteristics such as; shortening of the mandibular body, elongation of the anterior mandibular height, an obtuse gonial angle and an acute chin angle, a steeper slope of the body, posteroanterior mandibular rotation, and mandibular retrognathia, more so than subjects with incomplete UCLP. ${ }^{(31)}$

Research so far has focused on studying the craniofacial morphology of clefts in non-Arab populations. An investigation of the morphological variations in subjects with clefts in Saudi Arabia does not seem to have been reported. Therefore, the aim of this study was to determine if variations exist in craniofacial dimensions between cleft types, and to compare them with a control group.

\section{Materials and Methods}

The present study was undertaken at the Orthodontic department in the College of Dentistry, King Saud University in Riyadh, Saudi Arabia. Lateral cephalometric radiographs of non-syndromic individuals with clefts seeking treatment at the College were taken. Ninety three subjects (57 males and 36 females) representing three groups of patients with clefts were included. Forty nine patients 
presented with unilateral cleft lip and palate (UCLP), 27 patients had bilateral cleft lip and palate (BCLP), and 17 had cleft lip only (CL). Twenty eight subjects without clefts (18 males and 10 females) with Class I malocclusion acted as controls. The average age of the subjects was $15.8 \pm 3.7$ years (range, 11 to 27 years). Individuals with cleft palate only were not included due to the limited number of subjects present in this category.

\section{Cephalometric Tracing}

The Planmeca PM 2002 CC Proline Cephalostat (Instrumentarium Corp. Imaging Division, Tuusula, Finland) was used to obtain the lateral cephalometric radiographs. These radiographs were taken by trained radiographic technicians in a standardized manner using the same cepholstat. Each radiograph was traced on thin acetate paper manually under optimal illumination by one observer (EK). The cephalometric landmarks traced are shown in figure 1. Eight hard tissue landmarks were recorded ( $\mathrm{S}, \mathrm{N}, \mathrm{A}, \mathrm{B}, \mathrm{ME}, \mathrm{GN}, \mathrm{CO}, \mathrm{GO}$ ) and seven reference lines were constructed. From these, 2 angular (SNB, SN-MAND from GO-GN) and 4 linear (CO-GN, CO-GO, N-A, A-ME) variables were obtained. A steel ruler with a vernier gauge, accurate to one decimal place, was used to measure the linear reference lines.

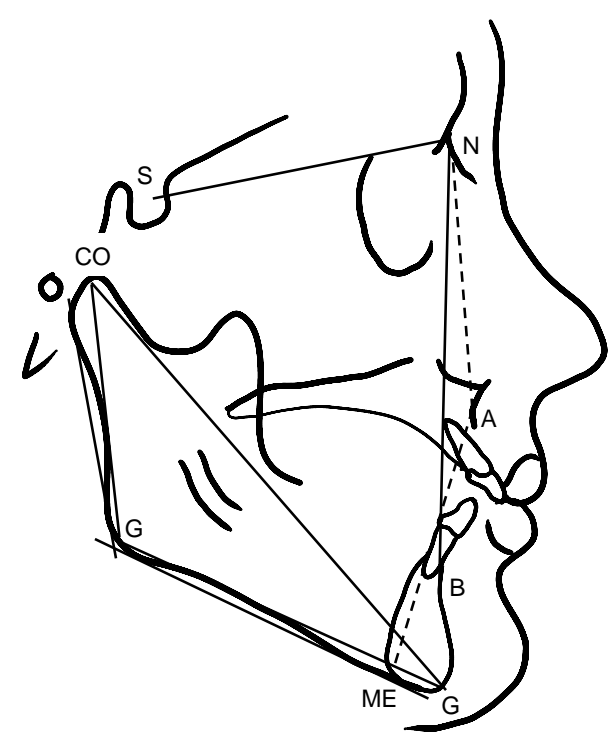

Fig.1. Landmarks and lines used in the cephalometric analysis 
Egyptian

Orthodontic Journal

\section{Duplicate determination of cephalometric landmarks:}

To reduce errors due to intra-operator variability, 20 lateral cephalometric radiographs of the cleft subjects, and 8 lateral cephalometric radiographs of the non-cleft subjects, were chosen at random and re-traced 3 weeks apart under identical conditions. Dalhbergs coefficient for assessment of intra-examiner error was used (1940), with the resulting measurements showing good reproducibility of the re-traced radiographs.

\section{Statistics:}

Statistical analysis was performed using the SPSS 10.0 for Windows ${ }^{\circledR}$ (SPSS Inc., Chicago, IL, USA). ${ }^{(33)}$ Comparison of the angular and linear measurement means of the four groups (male and female UCLP, BCLP, CL patients and male and female controls) was based on a factorial analysis of variance (ANOVA). Paired comparison of the groups was then performed with a post-hoc Duncan's test to allow for the multiple test situation. The significance level for all tests was set at $\mathrm{p} \leq 0.05$. Chi-square test was used for sex distribution.

\section{RESULTS}

Table 2 shows the cleft groups and sex distribution of the samples. No significant difference could be found among the cleft groups with regards to age and sex distribution.

SNB angle measurements also show no significant difference among UCLP, BCLP, CL and control groups. No significant difference could be found between male and female subjects either (Table 3).

SN-MAND angle measurement shows significant differences $(\mathrm{P}<0.01)$ among the groups (Table 3). The mean SN-MAND angle for the cleft groups (UCLP and BCLP) was significantly larger compared to that of the control group. SN-MAND angle for the $\mathrm{CL}$ and the control group was not significantly different. The BCLP group was statistically similar with the UCLP group in the SN-MAND angle, while it significantly differed from the CL group. There was no significant difference between the UCLP and the CL groups for the SNMAND angle. Sex had no significant effect on SN-MAND angle. 
Cleft groups (UCLP, BCLP and CL) were found to have significantly smaller linear measurements of CO-GN compared to the control group (0.01), while no significant differences were found among the cleft groups (Table 3). Females had significantly shorter CO-GN distances compared to males (0.001) (Table 3).

The mean CO-GO linear measurement of the control group was significantly larger than that of all cleft groups (UCLP, BCLP and CL) (0.0001). In contrast, CO-GO measurement was not significantly different among the cleft groups. Males were found to have significantly longer ramal heights (CO-GO) than that of females (0.05) (Table 4).

Table 1: Landmarks/Variables, and their definitions

\begin{tabular}{|c|l|}
\hline $\begin{array}{c}\text { Landmark/ } \\
\text { Variable }\end{array}$ & \\
\hline S & Sella; center of the hypophyseal fossa \\
\hline N & Nasion; the most anterior point on the frontonasal suture \\
\hline A & Most posterior point on anterior contour of upper alveolar process \\
\hline B & Most posterior point on anterior contour of lower alveolar process \\
\hline ME & Menton; most inferior point on mandibular symphysis \\
\hline GN & Gnathion; most anterior and inferior point of bony chin \\
\hline CO & $\begin{array}{l}\text { Condylion; most posterior superior point on the outline of the mandibular } \\
\text { condyle }\end{array}$ \\
\hline GO & $\begin{array}{l}\text { Gonion; the angle between the tangent to the lower border of mandible } \\
\text { and tangent to the mandibular ramus }\end{array}$ \\
\hline SNB & $\begin{array}{l}\text { Antero-posterior position of the mandible relative to the cranial base } \\
\text { measured from Sella-Nasion to B point (degrees) }\end{array}$ \\
\hline SN-MAND & Mandibular plane angle measured from Sella-Nasion to GO-GN (degrees) \\
\hline CO-GN & Effective mandibular length (mm) \\
\hline CO-GO & Effective ramal length (mm) \\
\hline N-A & Upper anterior facial height measured from Nasion to A point (mm) \\
\hline A-ME & Lower anterior facial height measured from point A to ME (mm) \\
\hline
\end{tabular}


Table 2: Group and sex distribution of the cleft patients.

\begin{tabular}{c|c|c|c}
\hline Group $^{\mathbf{1}}$ & Samples & Male & Female \\
\hline UCLP & $49(52.7 \%)$ & 29 & 20 \\
BCLP & $27(29.0 \%)$ & 14 & 13 \\
CL & $17(18.3 \%)$ & 14 & 3 \\
Total & 93 & 57 & 36 \\
\hline
\end{tabular}

${ }^{1}$ Abbreviations: see text.

Table 3: Means $( \pm$ SD) of angular measurements of cleft and control Subjects

\begin{tabular}{l|c|c|c|c|c}
\hline \multirow{2}{*}{ Measurement $^{1}$} & \multirow{2}{*}{ Group } & \multicolumn{2}{|c|}{ Sex } & \multirow{2}{*}{ Total } & \multirow{2}{*}{ P value } \\
\cline { 3 - 5 } & & Male & Female & & \\
\hline SNB $\left(^{\circ}\right)$ & UCLP & $77.1 \pm 4.2$ & $76.5 \pm 2.7$ & $76.8 \pm 3.7$ & \\
& BCLP & $75.2 \pm 2.7$ & $75.4 \pm 4.1$ & $75.3 \pm 3.4$ & \multirow{2}{*}{ NS } \\
& CL & $76.7 \pm 4.1$ & $74.6 \pm 1.5$ & $76.3 \pm 3.9$ & \\
& Control & $77.8 \pm 3.5$ & $77.9 \pm 3.0$ & $77.8 \pm 3.3$ & \\
& Total & $76.8 \pm 3.8$ & $76.4 \pm 3.2$ & & NS \\
\hline SN-MAND $\left(^{\circ}\right)$ & UCLP & $38.5 \pm 6.4$ & $37.8 \pm 5.8$ & $38.2^{\text {ab }} \pm 6.1$ & \\
& BCLP & $40.3 \pm 7.8$ & $40.9 \pm 4.5$ & $40.6^{\mathrm{a}} \pm 6.3$ & \multirow{2}{*}{$<0.01$} \\
& CL & $36.6 \pm 6.4$ & $37.3 \pm 4.0$ & $36.7^{\mathrm{bc}} \pm 5.9$ & \\
& Control & $35.7 \pm 4.7$ & $33.1 \pm 5.1$ & $34.7^{\mathrm{c}} \pm 4.9$ & \\
& Total & $37.8 \pm 6.4$ & $37.6 \pm 5.8$ & & NS \\
\hline
\end{tabular}

${ }^{1}$ Abbreviations: see text.

NS = Not Significant

Means with no common superscript are significantly different $(\mathrm{P}<0.05)$ for each measurement.

The N-A linear measurement in the UCLP group was found to be significantly smaller compared to the control group (Table 4). No significant difference was found among the BCLP, CL and the control group. In addition, neither of the cleft groups (UCLP, BCLP and CL) was significantly different than each other. The mean N-A measurement for males was found to be significantly larger than that of females (0.01).

Regarding the A-ME linear measurement, no significant difference was found among the UCLP, BCLP, CL and control groups. Males had significantly larger A-ME measurements than that of females (0.01) (Table 4). 
Egyptian

Orthodontic Journal

Table 4: Means $( \pm$ SD) of linear measurements of cleft and control subjects.

\begin{tabular}{l|l|l|l|l|l}
\hline \multirow{2}{*}{ Measurement $^{1}$} & \multirow{2}{*}{ Group } & \multicolumn{2}{|c|}{ Sex } & \multirow{2}{*}{ Total } & \multirow{2}{*}{ P value } \\
\cline { 3 - 5 } & & Male & Female & & \\
\hline CO-GN (mm) & UCLP & $122.0 \pm 9.4$ & $114.7 \pm 7.8$ & $119.0^{\mathrm{b}} \pm 9.4$ & $<0.01$ \\
& BCLP & $119.6 \pm 7.9$ & $115.1 \pm 7.0$ & $117.4^{\mathrm{b}} \pm 7.7$ & \\
& CL & $122.5 \pm 8.3$ & $116.0 \pm 8.8$ & $121.3^{\mathrm{b}} \pm 8.5$ & \\
& Control & $128.1 \pm 6.1$ & $122.1 \pm 3.1$ & $126.0^{\mathrm{a}} \pm 6.0$ & \\
& Total & $123.1 \pm 8.6$ & $116.5 \pm 7.3$ & & $<0.001$ \\
\hline CO-GO (mm) & UCLP & $56.8 \pm 6.1$ & $53.8 \pm 4.2$ & $55.5^{\mathrm{b}} \pm 5.6$ & $<0.0001$ \\
& BCLP & $56.9 \pm 5.5$ & $55.1 \pm 5.3$ & $56.0^{\mathrm{b}} \pm 5.4$ & \\
& CL & $59.2 \pm 6.4$ & $54.3 \pm 5.0$ & $58.4^{\mathrm{b}} \pm 6.3$ & \\
& Control & $61.9 \pm 4.9$ & $61.5 \pm 3.5$ & $61.7^{\mathrm{a}} \pm 4.4$ & \\
& Total & $58.5 \pm 6.1$ & $55.8 \pm 5.3$ & & $<0.05$ \\
\hline N-A (mm) & UCLP & $61.6 \pm 5.4$ & $57.8 \pm 4.1$ & $60.0^{\mathrm{b}} \pm 5.2$ & $<0.05$ \\
& BCLP & $63.6 \pm 5.3$ & $60.1 \pm 3.6$ & $61.9^{\mathrm{ab}} \pm 4.8$ & \\
& CL & $61.5 \pm 4.4$ & $61.3 \pm 2.3$ & $61.4^{\mathrm{ab}} \pm 4.0$ & \\
& Control & $64.6 \pm 2.7$ & $61.4 \pm 4.7$ & $63.4^{\mathrm{a}} \pm 3.8$ & \\
& Total & $62.6 \pm 4.8$ & $59.5 \pm 4.2$ & & $<0.01$ \\
\hline A-ME (mm) & UCLP & $66.9 \pm 6.5$ & $61.2 \pm 5.3$ & $64.6 \pm 6.6$ & NS \\
& BCLP & $64.2 \pm 7.0$ & $65.2 \pm 6.3$ & $64.7 \pm 6.6$ & \\
& CL & $67.8 \pm 4.1$ & $61.3 \pm 4.7$ & $66.7 \pm 4.8$ & \\
& Control & $68.6 \pm 4.1$ & $66.5 \pm 4.2$ & $67.8 \pm 4.2$ & \\
& Total & $67.0 \pm 5.8$ & $63.5 \pm 5.7$ & & $<0.01$ \\
\hline
\end{tabular}

${ }^{1}$ Abbreviations: see text.

NS = Not Significant

Means with no common superscript are significantly different $(\mathrm{P}<0.05)$ for each measurem

\section{DISCUSSION}

This study was conducted as an attempt to examine the mandibular dimensions and anterior facial height of individuals with UCLP, BCLP and CL, and to compare them to individuals without clefts. Results reveal that subjects with clefts involving the palate (UCLP and BCLP) displayed higher mandibular plane angles than subjects with cleft of the lip only, or the controls. The more severe the cleft (BCLP), the more obtuse the mandibular plane angle was. Previous cleft studies show similar findings with regards to the increased steepness of the mandibular plane and the obtuse gonial angle which were among the most common findings in cleft subjects. $(1,2,3,7,31,35)$ 
Differences in the dimensions of the mandible have also been noted previously. ${ }^{(3,5,6,7,11,24)}$ In a study conducted by Dahl et al in 1970, infants with cleft palate showed reduced mandibular dimensions (mandibular length and ramal height) in addition to higher mandibular and gonial angles (obtuse mandibular plane angles), when compared to infants with cleft of the lip only. They concluded that in infants with clefts, and before any surgical interference, significant differences in craniofacial morphology can be found which are more severe in the cleft palate group. ${ }^{(7)}$ Other researchers also agree that the type of cleft present influences mandibular morphology, and that growth and size of the mandible is significantly affected especially when the palate is involved. ${ }^{(3,5,6,11 \text {, }}$ ${ }^{24}$ ) In the current study, when the mandibular dimensions (mandibular length and ramal height) of the cleft subjects were compared with the controls, a significant difference was evident between both, where smaller mandibular dimensions was present more so in the cleft groups, especially in the female subjects. This is similar to a study performed by Hiyashi et al in which the craniofacial growth of UCLP subjects was compared with non-cleft controls. They concluded that a shorter ramus (measured from GO-ME) was found more frequently in cleft subjects, and that ramus height becomes smaller at 18 years of age in males, and after 12 years of age for females. ${ }^{(16)}$ This finding was also reported by other investigators on the same matter. ${ }^{(7,15,30)}$ Further differences found by Hiyashi et al in the cleft group were: an increased gonial angle; retrognathic chin position; shorter upper facial height and greater lower facial height. ${ }^{(16)}$

Differences in craniofacial morphology were also investigated by Ozturk et al where linear and angular variables were measured from tracings of lateral cephalometric radiographs of Turkish children with and without UCLP. ${ }^{(23)}$ Their results show that the UCLP children demonstrated a larger and steeper mandibular plane angle, a more obtuse gonial angle, and larger anterior facial height measurements than the control group. ${ }^{(23)}$ These deviations have been reportedly found in UCLP children prior to palatal surgery ${ }^{(32)}$ and in unoperated UCLP individuals. ${ }^{(3)}$

Various intrinsic and environmental factors have been shown to affect the craniofacial morphology in individuals with clefts. These factors influence mandibular growth and can include any or all of the following: intra-uterine disturbances, postnatal feeding difficulties, and surgical procedures during cleft repair. (4) Scott in 1954, hypothesized that muscle function determines the ultimate form of the mandible at the gonial angle, and that the reduced muscle activity accounts for the flattening of the area and the reduced bone apposition in the gonial angle. This in turn leads to the obtuse gonial angle and inclined 
mandibular plane of the cleft subjects. ${ }^{(26)}$ Ross (1970) reported that frequent respiratory infections and nasal septal deviations can alter mandibular posture in cleft lip and palate patients. He suggested that the habitual mouth opening and breathing pattern, together with the contracted maxillary arch and low palatal vault, caused the tongue to drop and as a result the mandible also dropped. (24) Shibasaki (1973) explained that the morphologic characteristics of the mandible were the result of the adaptations made in oral function as responses to small oral and pharyngeal cavities of cleft subjects. ${ }^{(30)}$

Unlike the mandibular dimensions, when the sagittal position of the mandible (SNB) was measured in the present study, no significant differences between neither cleft types (UCLP, BCLP, and CL), nor the control group could be found. This is similar to a study conducted by Ozturk et al in which 20 children with UCLP were compared with a control group of children without clefts. Their findings revealed no significant differences between both groups in the angular measurements of the SNB angle. ${ }^{(23)}$ On the other hand, a study conducted by Hiyashi et al on UCLP subjects reported that mandibular prognathism (SNB) was found to be smaller in cleft subjects than in controls. ${ }^{(16)}$

Considering the anterior facial height, the current study reveals a significant difference in the upper facial height between the cleft and the control groups. Further analysis shows that this significance was mainly the result between UCLP and control groups. When comparing both genders, females with clefts displayed smaller dimensions more so than the male clefts, or the controls. This is in agreement with Hyashi et al in which the upper facial height of cleft subjects (measured from nasion to the nasal floor), was found to be less than that of the controls, especially in older subjects. They further explained that this may occur due to the deceleration of the downward development of the anterior part of the nasal floor. ${ }^{(16)}$ The reduction of upper face height was also reported by Bishara et al (1985) in unoperated UCLP children, ${ }^{(3)}$ and in UCLP children prior to palatoplasty. ${ }^{(32)}$ Latham (1969) suggested that this reduction may result from impairment in the interaction between the maxilla and the growth-regulating nasal septum. ${ }^{(20)}$

Contrary to the upper facial height, the lower anterior facial height was similar in both cleft subjects and controls. The only significant difference found was between the female and male cleft subjects, where the females showed a more reduced lower anterior facial height than the males. Treutlein et al (2002) studied the craniofacial morphology of 10 year old males and females with UCLP and compared them with a control group. Similar to the current study, their results show that the lower facial height did not increase in cleft patients 
(ANS-Men), but no difference between genders could be found. ${ }^{(34)}$ They further explained that the simultaneously reduced bony chin prominence and the significantly shorter mandibular length (Co-Gn) are typical features of UCLP patients, which explain why the lower facial height is not significantly increased despite the posterior rotation of the mandible.

\section{Conclusions}

Obtuse mandibular plane angles can be expected in subjects with clefts involving the palate (UCLP or BCLP). Individuals with clefts display certain morphological characteristics such as high mandibular plane angles, smaller mandibular and gonial lengths, and shorter upper facial height when compared to subjects without clefts. Larger dimensions are present more so in males than females with clefts, but are still considered smaller than the control group.

\section{REFERENCES}

1. Aduss H, Pruzansky S, Miller M. Interorbital distance in cleft lip and palate. Teratology. 4:171,1971.

2. Bimm JA. Cleft palate morphology of the human mandible. Am J Orthod. 46:791, 1960.

3. Bishara SE, DeArrendondo RSM, Vales HP, Jakobsen JR. Dentofacial relationships in persons with unoperated clefts: comparisons between three cleft types. Am J Orthod. 87:481, 1985.

4. Borden GH. Mandibular growth in the cleft palate infant. Angle Ortho. 27:197, 1957.

5. Capelozza Junior L, Taniguchi SM, da Silva Junior OG. Craniofacial morphology of adult unoperated complete unilateral cleft lip and palate patients. Cleft Palate Craniofac J. 30:376, 1993.

6. Corbo M, Dujardin T, Maertelaer V, Malevez C, Glineur R. Dentocraniofacial morphology of 21 patients with unilateral cleft lip and palate: A cephalometric study. Cleft Palate Craniofacial Journal. 42:618, 2005.

7. Dahl E. Craniofacial morphology in congenital clefts of the lip and palate. Acta Odontol Scand. Suppl. 57, 1970.

8. Dahl E, Kreiborg S, Jensen BL, Fogh-Andersen P. Comparison of craniofacial morphology in infants with incomplete cleft lip and infants with isolated cleft palate. Cleft Palate Journal. 19:258, 1982. 
9. Dahlberg G. Statistical methods for medical and biological students. George Allen and Unwin, London. 1940.

10. Diah E, Lo LJ, Huang CS, Sudjatmiko G, Susanto I and Chen YR. Maxillary growth of adult patients with unoperated cleft: answers to the debates. Journal of Plastic, Reconstructive \& Aesthetic Surgery. 60:407, 2007.

11. Filho S, Normando A, Filho L. Mandibular growth in patients with cleft lip and palate-the influence of cleft type. Am j Orthod Dentofacial Orthop. 104:269, 1993.

12. Gesch D and Kirbschus A. Complete cleft lip and palate without bone grafting and its effect on craniofacial morphology in three planes. Ann Anat. 186:531, 2004.

13. Gorlin RJ, Cervenka J, Pruzensky S. Facial clefting and its syndromes. Birth Defects 7:3, 1971.

14. Gregg T, Boyd D, Richardson A. The incidence of cleft lip and palate in Northern Ireland from 1980-1990. Br J Orthod. 21:387, 1994.

15. Hama K. Morphological study of the craniofacial skeleton within a profile in cleft lip and palate J Osaka Univ Dent School. 4:41, 1964.

16. Hayashi I, Sakuda M, Takimoto K, Miyazaki. Craniofacial growth in complete cleft lip and palate: A roentgeno-cephalometric study. Cleft Palate J. 13:215, 1976.

17. Johar AA, Ravichandran K, Subhani SN, Jarba EA. Cleft Lip/ Palate and Craniofacial Anomalies, 1999-2005. King Faisal Specialist Hospital and Research Centre, Riyadh, Saudi Arabia, 2006

18. Laitinen J. Association between dental consonant articulation, orofacial morphology and function in cleft lip/palate. Department of Pedodontics and Orthodontics, Institute of Dentistry, University of Helsinki, Helsinki. 1999.

19. Laspos CP, Kyrkanides S, Tallents RH, Moss ME, Subtelny JD. Mandibular and maxillary asymmetry in individuals with unilateral cleft lip and palate. Cleft Palate Craniofac J. 34:232, 1997.

20. Latham RA. The pathogenesis of skeletal deformity associated with unilateral cleft lip and palate. Cleft Palate J. 6:404, 1969.

21. Lo LJ, Wong FH, Chen YR and Wong HF (2002). Mandibular Dysmorphology in Patients with Unilateral Cleft Lip and Cleft Palate. Chang Gung Med J. 25: 502, 2002. 
22. Osuji OO, Ogar DI, Akande OO. Cleft lip and palate as seen in the University College Hospital, Ibadan. West Afr J Med. 13:242, 1994.

23. Ozturk Y, Cura N. Examination of craniofacial morphology in children with unilateral cleft lip and palate. Cleft Palate-Craniofacial Journal 1996;33:32-36.

24. Ross RB. The clinical implications of facial growth in cleft lip and palate. Cleft Palate J. 7:37, 1970.

25. Ross RB. Treatment variables affecting facial growth in complete unilateral cleft lip and palate. Cleft Palate Craniofacial J. 24:5, 1987.

26. Scott JH. The growth and function of the muscles of mastication in relation to the development of the facial skeleton and the dentition. Amer $\mathrm{J}$ Orthodont. 40:429, 1954.

27. Shapira Y, Lubit E, Kuftinec MM, Borell G. The distribution of clefts of the primary and secondary palates by sex, type and location. Angle Orthod. 69:523, 1999.

28. Shetye PR. Facial growth of adults with unoperated clefts. Clin Plast Surg. 31:361, 2004.

29. Shetye PR and Evans CA. Midfacial Morphology in Adult Unoperated Complete Unilateral Cleft Lip and Palate Patients. Angle Orthodontist 76:810, 2006.

30. Shibasaki Y. A roentgenocephalometric study of dentocraniofacial morphology of repaired unilateral cleft lip and palate individuals after adolescent growth spurt. Kokubyo Z . 476, 1973.

31. Smahel Z, Brejcha M. Differences in craniofacial morphology between complete and incomplete unilateral cleft lip and palate in adults. Cleft Palate J. 20:113, 1983.

32. Smahel Z, Mullerova Z. Craniofacial morphology in unilateral cleft lip and palate prior to palatoplasty. Cleft Palate J. 23:225, 1986.

33. SPSS, 1999. Statistical Package for Social Science, Version 10, SPSS Inc, USA.

34. Treutlein C, Berten JL, Swennen G, Brachvogel P. Comparative cephalometric study of 10-year-old patients with complete unilateral cleft lip and palate. Journal of Orofacial Orthopedics. 64:27, 2003.

35. Vora JM, Joshi MR. Mandibular growth in surgically repaired cleft lip and palate individuals. Angle Orthod. 47:403, 1977.

36. Wilson ME. A ten-year survey of cleft lip and cleft palate in the South West Region. Br J Plast Surg. 25:224, 1972. 